\title{
Transport and health expertise can help meet the World Health Organization's goals for global climate change and noncommunicable disease prevention
}

\section{Professor Jennifer S Mindell}

\section{j.mindell@ucl.ac.uk}

Health \& Social Surveys Research Group

Dept Epidemiology \& Public Health

UCL

1-19 Torrington Place

London WC1E 6BT

Tel +44-20-7679-1269

At the opening of the conference of the International Society for Physical Activity and Health (http://www.ispah.org/london-2018/) in October, we were reminded that the science of physical activity and health began with Morris's study of bus drivers and bus conductors (Morris \& Raffles, 1954). Both incidence of and mortality from ischaemic heart disease were lower among conductors than drivers, two groups of men from similar demographic and socio-economic groups and with the same working environment - at first glance. Morris hypothesised that this difference in heart disease was due to a beneficial effect of physical activity: drivers were sedentary while conductors walked and climbed stairs all day (as they worked on double-decker buses, collecting fares). Physical inactivity is not the only hazard for professional drivers: Senthanar and colleagues (2018, this issue) examining musculoskeletal problems among truck drivers find a high proportion of modifiable factors associated with the drivers' high prevalence of musculoskeletal problems.

Having begun with occupational activity, the physical activity research field then largely moved focus to leisure-time activity. In the past couple of decades, researchers as well as policy-makers and practitioners have given greater consideration to physical activity occurring during travel, i.e. "active travel". Walking and bicycling are the most obvious modes of active travel, but some researchers include public transport given that use of buses for travel is associated with greater travel-related physical activity among passengers (Coronini-Cronberg, 2012). In this issue, Patterson et al (2018) report that uptake of the free bus pass was greater among study participants from minority ethnic groups. Given that members of minority ethnic groups in England have lower average levels of leisure-time physical activity, free bus travel may be of particular importance to this group. Work by Reinhard and her colleagues (2018) suggests that the free bus pass has increased actual use of public transport. They also showed that use of the free bus travel also improves memory and reduces loneliness and depression. This fits with McCarthy and Habib's finding, reported in this issue, that daily travel is associated with life satisfaction (McCarthy and Habib, 2018).

Travelling on foot or by bicycle instead of by car avoids imposing risk on others through air pollution (WHO, 2017), noise (Babisch, 2008), injury (Scholes et al, 2018), or community severance (Bradbury 
2014), in addition to the personal health benefits from physical activity. Riiser and colleagues (2018, in this issue) show cross-sectional associations between cycling for travel and lower adjusted odds of obesity, self-reported diabetes, and low levels of high density lipoprotein (HDL)-cholesterol, even after taking into account walking, leisure physical activity, and socio-demographic factors in a multiethnic sample of people in Oslo, Norway living in low socio-economic areas. Walking for travel in this cross-sectional sample was inversely associated with raised systolic blood pressure. In France, as reported by Menai et al. (2018), objective measures of obesity, including abdominal obesity and percentage body fat, were inversely related to self-reported walking $>2.5 \mathrm{~h} /$ week in women, while cycling $>1.5 \mathrm{~h} /$ week was associated with the same health measures in men and women, with larger effect sizes in men. The greatest difference was among those who used both travel modes; walking had a smaller association than cycling.

Recognition of the importance of air pollution and its contribution to disease and inequalities has been rising recently. The World Health Organization has now included air pollution as a major health risk contributing to noncommunicable diseases (NCDs). A study conducted in Barcelona in 2011 found that although travel accounted for only $6 \%$ of people's time, it contributed $11 \%$ of their exposure to $\mathrm{NO}_{2}$, and $24 \%$ of the $\mathrm{NO}_{2}$ they inhaled (de Nazelle et al, 2013). Helping individuals select a route to reduce their exposure to air pollution might therefore be welcomed. However, Haddad and de Nazelle (2018) report in this issue that an app to do so did not influence travel-related behaviour despite participants' prior expectations. Knowledge is only one of the factors influencing people's behaviour - a fact that is often forgotten in policy-making.

The 2018 resolution of the World Health Assembly includes a goal to reduce physical inactivity by $10 \%$ by 2025 and $15 \%$ by 2030 (WHO, 2018a). The World Health Organization (WHO) has now launched a technical package to help countries achieve these goals (WHO, 2018b). Ambient air pollution causes almost $8 \%$ of noncommunicable diseases globally, particularly in middle income countries (WHO, 2017). Both air pollution and physical inactivity can be addressed by a shift from private motor cars to active travel, particularly through fostering a popular culture of valuing physical activity, creating active environments, and taking a whole systems approach, helping to meet Sustainable Development Goals and improving health in every country worldwide, regardless of their national income or Human Development Index. Effective approaches include improved urban planning and compact cities, where journeys are shorter and less car-dependent, combined with improvements in public transport (WHO, 2017) but it is disappointing that the focus is on replacement of older diesel vehicles alone rather than changing infrastructure and promoting a culture of minimising car use. Even with electric cars powered by green energy sources, the problems of particulate air pollution from brakes and tyres persist (Padoan and Amato, 2018). Researchers, policy-makers and practitioners in the field of transport and health can play a major role in generating, disseminating and implementing evidence-based policies and interventions to help achieve the WHO goals for activity and for outdoor air pollution. Together we can push for effective changes to the environments in which people make their choices. I hope that the Journal of Transport and Health - and many articles in this issue - are making their contribution.

\section{Funding}

No funding was received for this editorial. 


\section{Conflict of interest.}

I am a co-author of one of the papers published in this volume of Journal of Transport and Health and mentioned in this editorial. Every manuscript authored by an editor is always processed in the same way as any other submission except that it is handled only by other editors.

\section{References}

Appleyard BS, Christopher E. Ferrell. The Influence of crime on active \& sustainable travel: New geostatistical methods and theories for understanding crime and mode choice. Journal of Transport \& Health, Volume 6, 2017, Pages 516-529, https://doi.org/10.1016/i.jth.2017.04.002

Babisch W. Road traffic noise and cardiovascular risk. Noise Health. 2008;10:27-33

Bradbury A. Understanding Community Severance and ts Impact on Women's Access and Mobility in African Countries - Literature Review. 2014.

Coronini-Cronberg S, Christopher Millett, Anthony A. Laverty, Elizabeth Webb. The Impact of a Free Older Persons' Bus Pass on Active Travel and Regular Walking in England. Am J Public Health. 2012;102(11): 2141-2148. doi: 10.2105/AJPH.2012.300946

Evers C, Shawn Boles, Deb Johnson-Shelton, Marc Schlossberg, David Richey. Parent safety perceptions of child walking routes. Journal of Transport \& Health, Volume 1, Issue 2, 2014, Pages 108-115. https://doi.org/10.1016/j.jth.2014.03.003

Haddad $\mathrm{H}$, de Nazelle A. The role of personal air pollution sensors and smartphone technology in changing travel behaviour. Journal of Transport \& Health, 2018

https://doi.org/10.1016/i.jth.2018.08.001.

McCarthy S, Habib MA. Investigation of life satisfaction, travel, built environment and attitudes. Journal of Transport \& Health, Volume 11, 2018, Pages 15-24, https://doi.org/10.1016/j.jth.2018.09.007.

Menai M., Charreire, H., Galan, P., Simon, C., Nazare, J.-A., Perchoux, C., Weber C, Enaux C, Hercberg S, Fezeu L, Oppert, J.-M. (2018). Differential Associations of Walking and Cycling with Body Weight, Body Fat and Fat Distribution - the ACTI-Cités Project. Obesity Facts, 11(3), 221-231. http://doi.org/10.1159/000488532

Methorst 2017a: Methorst R, Paul Schepers, Nicola Christie, Martin Dijst, Ralf Risser, Daniel Sauter, Bert van Wee. Pedestrian falls' as necessary addition to the current definition of traffic crashes for improved public health policies. Journal of Transport \& Health, Volume 6, 2017, Pages 10-12. https://doi.org/10.1016/j.jth.2017.02.005

Methorst 2017b: Methorst R, Paul Schepers, Nicola Christie, Bas de Geus. How to define and measure pedestrian traffic deaths? Journal of Transport \& Health, Volume 7, Part A, 2017, Pages 10 12 https://doi.org/10.1016/j.jth.2017.09.008

Morris JN, Raffles PAB. Coronary heart disease in transport workers. A progress report. Br J Industr Med. 1954, 11, 260-264.

de Nazelle A, Edmund Seto, David Donaire-Gonzalez, Michelle Mendez, Jaume Matamala, Mark J. Nieuwenhuijsen, Michael Jerrett. Improving estimates of air pollution exposure through ubiquitous 
sensing technologies. Environmental Pollution. Volume 176, 2013, Pages 92-99.

https://doi.org/10.1016/i.envpol.2012.12.032.

Padoan E, Amato F. Chapter 2 - Vehicle Non-Exhaust Emissions: Impact on Air Quality. In Amato F (Ed). Non-Exhaust Emissions. Academic Press, 2018, Pages 21-65. ISBN 9780128117705.

https://doi.org/10.1016/B978-0-12-811770-5.00002-9.

Patterson R, Webb E, Mindell JS, Millett C, Laverty AA. Ethnic group differences in impacts of free bus passes in England: A national study. Journal of Transport \& Health, Volume 11, 2018, Pages 1-14. https://doi.org/10.1016/j.jth.2018.09.005.

Reinhard E, Courtin E, van Lenthe FJ, Avendano M. Public transport policy, social engagement and mental health in older age: a quasi-experimental evaluation of free bus passes in England. $J$ Epidemiol Community Health.2018;72:361-368. doi: 10.1136/jech-2017-210038.

Riiser A, Ane Solbraa, Anne Karen Jenum, Kåre I. Birkeland, Lars Bo Andersen. Cycling and walking for transport and their associations with diabetes and risk factors for cardiovascular disease. Journal of Transport \& Health, 2018,

https://doi.org/10.1016/i.jth.2018.09.002.

Rothman L, Ron Buliung, Teresa To, Colin Macarthur, Alison Macpherson, Andrew Howard. Associations between parents' perception of traffic danger, the built environment and walking to school. Journal of Transport \& Health, Volume 2, Issue 3, 2015, Pages 327-335.

https://doi.org/10.1016/i.jth.2015.05.004

Scholes S, Wardlaw MJ, Heydecker B, Mindell JS. Risks in driving and cycling including third-party deaths in Great Britain 2005-2013: a population-based repeated cross-sectional study. J Transp Health. 2018;8:321-33. https://doi.org/10.1016/j.jth.2017.11.143

Senthanar S, Philip L. Bigelow, Factors associated with musculoskeletal pain and discomfort among Canadian truck drivers: A cross-sectional study of worker perspectives, Journal of Transport \& Health, 2018, $\quad$ https://doi.org/10.1016/j.jth.2018.08.013.

UN 2015. United Nations. Transforming our world: The 2030 Agenda for Sustainable Development. New York, UN, 2015.

https://sustainabledevelopment.un.org/post2015/transformingourworld/publication

WHO 2017. World Health Organization. Preventing noncommunicable diseases (NCDs) by reducing environmental risk factors. Geneva: WHO, 201.

WHO 2018a. World Health Organization. Global action plan on physical activity 2018-2030: more active people for a healthier world. Geneva: WHO, 2018. www.who.int/ncds/prevention/physicalactivity/global-action-plan-2018-2030/en/

WHO 2018b. Active. A technical package for increasing physical activity. Geneva: WHO, 2018. www.who.int/ncds/prevention/physical-activity/active-toolkit/en/ 